\title{
The Necessity of the Field AC Withstand Voltage Test for GIS Operation
}

\author{
Shi Feng, Wang Qinghao, Huang Dongwei, Shi Yan, Hai Tianshu, Huang \\ Yanhai, Liu Guobin, Zhang Ning, Wang Enlu, Li Xinyu, Shi Dongpeng
}

Fushun Power Supply Company, Liaoning Electric Power Company Limited, State Grid, China, fushunpowersupply@163.com

Keywords: The GIS system; AC withstand voltage; Test and application; Failure analysis

\begin{abstract}
This article illustrates the characteristics and proportion of GIS system failure through the introduction to GIS system structure and characteristics; In order to make the GIS in the safe operation of the power system, It is necessary to test AC withstand voltage at the scene.
\end{abstract}

\section{Introduction}

With the development of modern electric power industry, our new substation is mostly on the GIS substation (Combination electric appliance of SF6 gas appliances).It has many unique advantages such as small floor space, convenient maintenance, reliable operation and so on . but the failure of GIS substation is more serious than open substation's. Through a large number of experiment, it proves that AC withstand voltage test at the scene of the GIS system can discover the insulation of the GIS system defects preferably, and avoid the happening of the accident, also ensure the safe operation of power system[1-3].

GIS makes all primary equipment except the transformer in a substation to be an organic combination whole by optimization design-generally modular structure, called "gas insulated substation". In general, it consists of eight parts-the circuit breaker (CB), the isolating switch (DS), earthing switch (ES), voltage transformer (TV), current transformer (TA), lightning arrestor (LA), BUS (BUS) and the casing (BSG). These all are enclosed within a grounded metal shell, shell is filled with SF6 gas ( $0.3 \sim 0.4 \mathrm{~Pa})$ to ensure reliable insulation of to ground, phase-to-phase and the fracture. As shown in Figure 1.

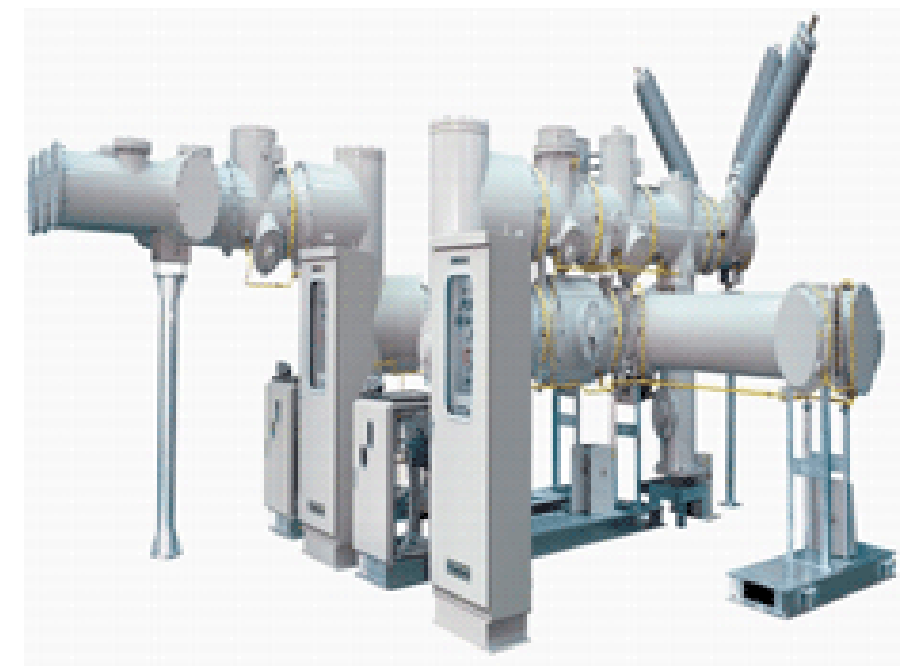

Figure 1 An interval of GIS equipment in $66 \mathrm{kV}$ substation

\section{The cause of GIS test}

The GIS need to take adjustment test after in the factory after redelivery assembling, then transport to the field for installation as the form of transportation unit. Mechanical vibration and impact in the process of transportation may cause the original GIS or assembly fasteners to loose or 
being relative displacement[4,5]. There may be some mistakes in coupling sealing process and so on when installation, which lead to the electrode surface scratch or dislocation installation and then cause the electrode surface defects. Floating dust in the air conductive particulate impurities and burr at the scene of the installation are difficult to clean up and check out, It will cause insulation accident. As shown in Figure 2

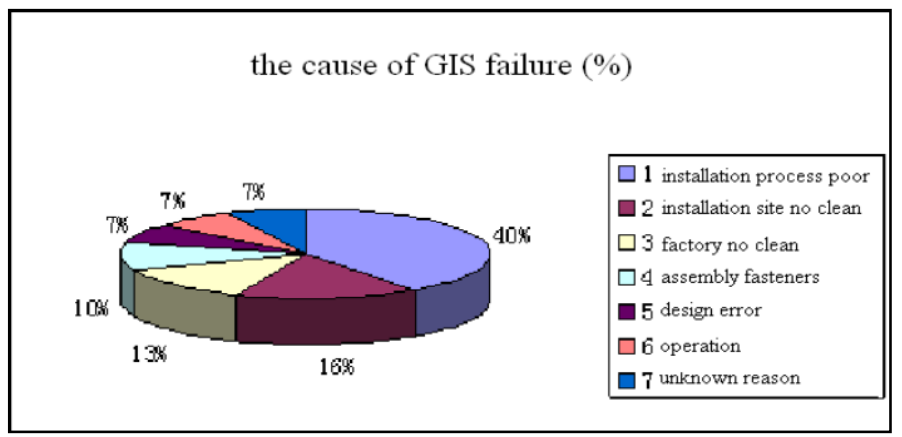

Figure 2 The proportion of GIS failure

Accident statistics show that GIS can effectively eliminate the fault that after the AC withstand voltage. Although we cannot ensure that GIS couldn't appear insulation accidents in the running after withstand, but the GIS after AC withstand voltage test are mostly reduce the accidents, so GIS must take field withstand voltage test.

\section{AC withstand voltage test requirements of GIS on the spot}

GIS should be fully installed, SF6 gas filling to rated density, main circuit resistance measurements, each component test the content of SF6 micro water and leak test have been completed. And all current transformers secondary windings are grounded, voltage transformer secondary windings are open and grounded.

The following equipments should be isolated from the GIS before AC withstand voltage test: high voltage cable and bus; transformer and most electromagnetic voltage transformer; Lightning arrester and Safety spark gap.

Every new installation area of GIS should be, at the same time, Original parts of adjacent equipment should be outage and grounded when testing withstand voltage to extension. Otherwise, a sudden breakdown will bring bad effects for of original equipment.

3.4experiment proves that the weather has much effect on the $\mathrm{Q}$ value; $\mathrm{Q}$ value will be reduced $30 \%-40 \%$ in cloudy or humidity larger weather, so the test best choose dry or sunny weather.

\section{Pressure method of the test}

The schematic diagram of AC withstand voltage test is shown in Figure 3.

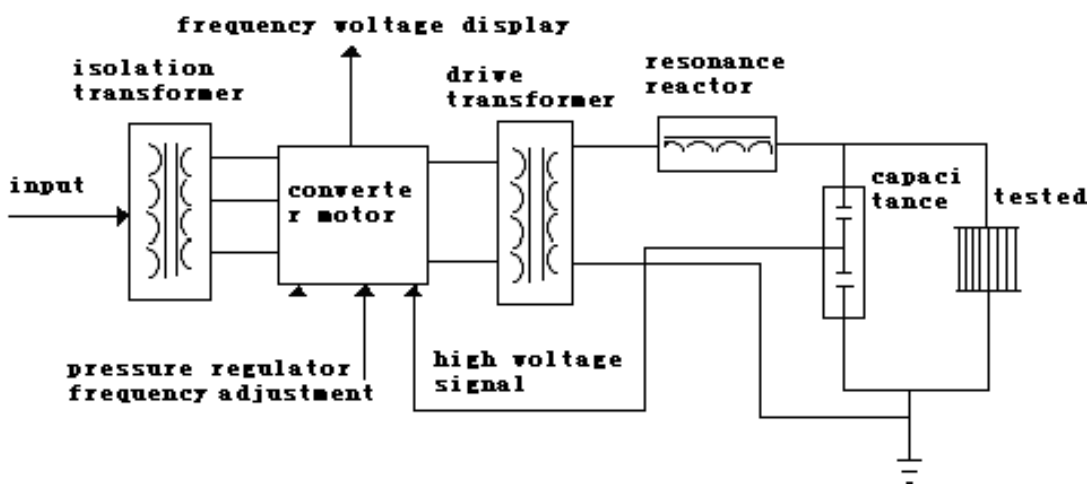

Figure 3 The schematic diagram of Variable frequency series resonance test 
Test voltage is applied between each phase conductor and the, the test is made in units of sep phase irately, others connect to the shell and ground, pressure from outlet and inlet line string, it should make every component of the GIS be applied once test voltage at least in the test. At the same time, in order to avoid insulation aging on account of the same part withstanding voltage many times, the test voltage is applied in several parts as much as possible. It generally takes relatively AC withstand voltage test on the spot, if the isolating switch of circuit breaker was damaged or disintegrated during transportation or installation procedure, it should be make AC withstand voltage test in the port, Pressure-withstanding value is consistent with the AC withstand voltage value of phase to grounding, if the capacitance of GIS is larger, withstand voltage test can be done in several stages.

\section{The test procedures of AC Withstand Voltage}

The first stage of AC Withstand Voltage test in the GIS field is "sophisticated purification" (sophisticated test), this purpose is to remove the possible existence conductive particles or non conductive particles in the internal of GIS. These particles may be due to the uncleanness at installation time, or the metal chips after multiple operations, or being formed by fastener cutting debris and burr at the surface of the electrode. "sophisticated purification" can make the electrical conductive particles move to low ground varticle trap and burr at the surface of ablation electrode, so that it is less than insulation damage effect."The voltage of "Sophisticated purification" should be lower than Withstand voltage, and the time may take several minutes. "Sophisticated purification" does not take the place of AC withstand voltage test. The second stage is AC withstand voltage test after "sophisticated purification", the time is $1 \mathrm{~min}$. The relationship between voltage and time in sophisticated test is shown as Figure 4

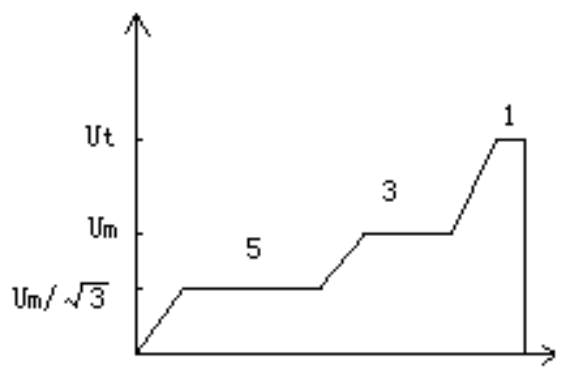

Figure 4 The relation curve between the additive voltage and time

Where, Um/1.732 is phase voltage of system maximum voltage; Um is the system maximum voltage; Ut is testing voltage.

\section{The result judgment of withstand voltage test}

1) If each parts of GIS have been withstander the selected test voltage as the stipulated and complete test procedure without breakdown discharge, seen as the GIS through experiment.

2) Breakdown discharge in the process of test should be according to the discharge energy and the discharge caused by all kinds of the discharge effect such as sound, light, electricity, chemistry, and the test results of fault diagnosis technology in the process of the pressure test ., it can take the following steps In case of discharge condition:

3) Conduct repeatable tests by applying the regulation voltage, if the device or traps can withstand, it is self-recovery discharge. If the repeatable test voltage reaches constant value and time, it is considered unqualified, or else according to the next item.

4) Disintegrate the equipment, open the discharge traps, and then check the insulation condition carefully. The next pressure test can be done after the necessary restoration measure

5) The living example of AC Withstand Voltage

Case 1, Cheng Dong second line always could not switch on when power transmission in Cheng 
Dong in $66 \mathrm{kV}$ substations, it didn't find any grounding place after checking several times for the transmission lines, and could be found certain insulation. Tested the withstand voltage after switching off the GIS and line. Then we found the disk insulator of disconnect or in Cheng Dong second line appeared rift , and its insulation resistance was $0 \mathrm{~m} \Omega$,as shown in Figure 5.

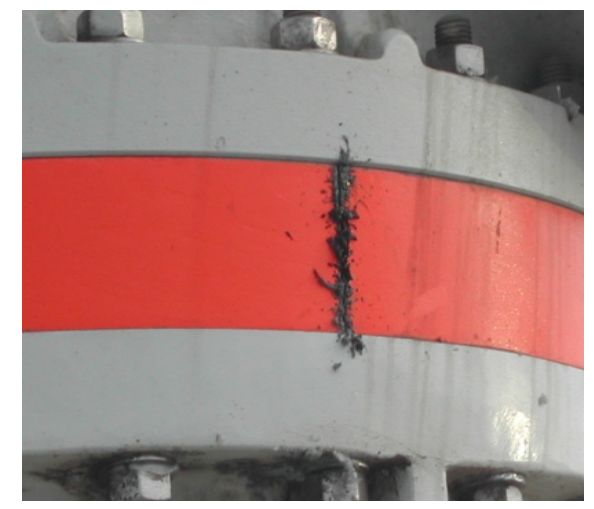

Figure 5 the rift of disk insulator

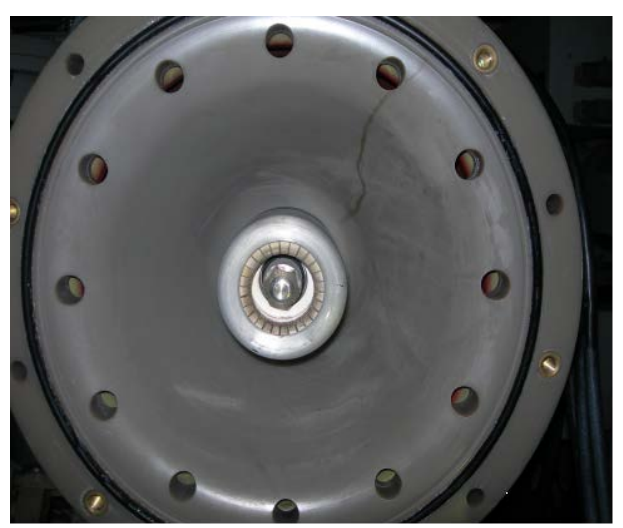

Figure 6 The arc-over of disk insulator

It is found that the disk insulator between phase A Circuit breaker and disconnector was arc-over when the alternating voltage reaching $109 \mathrm{kV}$ in the Commissioning Test for the GIS of LinBei first line in LiuLin 220kV substation, as shown in Figure 6.

\section{Conclusion}

If testing withstand voltage for the Segmentation GIS , the inlet and outlet gaps are more , and self-recovery discharge or breakdown during the test is difficult to determine the location by the human ear, so it should use fault locator on site. It can get twice the result with half the effort supposing that install the sensor on the subjects of a hood and listen to the part of the discharge before each pressure test.

\section{References}

[1] LuoXuesen. Insulation Whole Sealing. China Electric Power Press.2003.9

[2] ChenHuagang. Electrical Equipment Preventability Testing Method and Diagnostic Techniques. China Water Conservancy Power Press, 2009

[3] CaoJianzhong. Electrical Test. China Electric Power Press, 2005

[4] ZhangXiaohui. Electrical Test (Skill Training Teaching Material) . China Electric Power Press. 2010

[5] Chen Huagang. Electrical equipment preventive test techniques for question answering. Hydraulic and electric power press, 1998 